\title{
631 INTERNATIONAL RADIO CONFERENCES
}

$\mathrm{D}^{2}$ URING the summer of 9 there were a number of international metils in Europe on various aspects of radio research, development and operation. Three of these were holy in Stockholm during July, while some of the fthds pook place in Brussels, Copenhagen anf Lond on (see Nature, 161, 695; 1948).

The foterationa Bcentific Radio Union (U.R.S.I.) held its Eighth Goneral Assembly in Stockholm durt. July 13-24. Beginning concurrently with this meeting, the Fifth Reunion of the International Consultative Committee on Radiocommunication (C.C.I.R.) was also held in Stockholm. On the termination of the U.R.S.I., a brief meeting of the Joint Commission on Radio-Meteorology was held in the same place. Later, in Brussels, during July 28-30, there was a meeting of the Mixed Commission on the Ionosphere. At all these meetings the subjects discussed included various scientific and technical matters on which international collaboration or agreement is necessary in order to advance our knowledge of radio science and its application to radio communication, broadcasting and navigation. The above meetings were followed by a British Commonwealth Specialist Conference on Radio Research held in London during August 4-6. This formed a very convenient occasion to review the various recommendations made by the international assemblies, and to agree on an appropriate distribution of responsibility, within the Commonwealth, of the British contribution to the international research programme.

\section{Wave-lengths for Broadcasting}

Reference has already been made in Nature (162, $562 ; 1948)$ to the European Broadcasting Conference in Copenhagen, where over a period of some ten weeks a new plan was produced for a revised allocation of wave-lengths to broadcasting stations in Europe. The Copenhagen plan, 1948, as it is called, will come into operation on March 15, 1950, when some 340 stations and synchronized networks will be accommodated in 139 channels in the long (frequencies 150-285 kc./s.) and medium (525-1,605 kc./s.) wave portions of the radio spectrum allotted exclusively for broadcasting. Details of the new wavelengths, with the frequency and power assigned to each station, are given in the Wireless World of November 1948.

\section{Resolutions of the U.R.S.I. and C.C.I.R.}

Reverting to the two major conferences, which are concerned with scientific research and development, some brief details of the resolutions and recommendations of the U.R.S.I. and C.C.I.R. are given below. The International Scientific Radio Union, the president of which is Sir Edward Appleton, after considering the extension of the radio field, decided to replace the four commissions, into which it was previously organised, by seven commissions. The titles and presidents of these are as follows: (I) Measurements and Standardization, Dr. J. H. Dellinger (U.S.A.); (II) Troposphere and Wave Propagation, Dr. C. R. Burrows (U.S.A.); (III) Ionosphere and Wave Propagation, Sir Edward Appleton (Great Britain); (IV) Terrestrial Atmo- spherics, Prof. H. Norinder (Sweden); (V) Extraterrestrial Radio Noise, Dr. D. F. Martyn (Australia); (VI) Waves and Oscillations, Prof. B. van der Pol (Netherlands); (VII) Electronics, Dr. G. Lehmann (France).

The C.C.I.R. conference was held under the presidency of Dr. H. Sterky, director-general of telegraphs in Sweden, and was attended by delegates from more than thirty nations. A large proportion of its work at Stockholm consisted in surveying a number of technical questions put forward by the Atlantic City meeting of the International Telecommunications Union. Only a preliminary exam. ination of these subjects could be carried out in most cases ; and at the termination of the meeting, the plenary assembly of the C.C.I.R. set up thirteen international study groups to carry out preparatory surveys and submit reports for the next reunion, which is to take place in 1951. The subjects for study included various aspects of radio transmitters and receivers, wave propagation along the ground and through the lower and upper atmosphere, time signals and standard frequencies, and certain ques. tions relating to broadcasting and television. During the Stockholm meetings, recommendations were made that Prof. B. van der Pol, of the Netherlands, should be appointed director, and Mr. L. W. Hayes, of the British Broadcasting Corporation, vice-director of the C.C.I.R. Both appointments were to be taken up in January 1949.

Some of the conclusions and resolutions on scientific matters reached by the various conferences are referred to briefly in the following sections.

\section{Radio Standards and Measurements}

It was strongly recommended by the U.R.S.I. and the C.C.I.R. that the study of field-strength measurement over the whole frequency spectrum should be continued, and that the interchange of equipment between the various national laboratories should be encouraged. In addition, the U.R.S.I. urged that a study of standard noise sources of various types should be carried out, and that investigations should be made of the various methods of measuring radiofrequency power, particularly at frequencies above a few hundred megacycles per second.

On the question of standard frequency transmissions, the C.C.I.R. stated that there is an urgent need to put into operation additional standard frequency and time stations, perhaps in the United Kingdom and in Australia, to serve the now inadequately served areas of the world. Such stations should operate on the frequencies assigned for the purpose at the Atlantic City Conference in 1947, and it was recommended that an international study group should organise and control experiments to determine the effective service areas and the zones of interference with the existing emissions from Washington (Station $W W V$ ).

The Commonwealth Conference urged that the plans for the establishment of a standard frequency service in the United Kingdom should be pursued, and that both Australia and South Africa should establish similar services, if possible.

A further recommendation of some interest is that all standard-frequency stations should periodically 
and simultaneously interrupt their transmissions to permit measurement of natural radio noise, suitable programmes for this purpose to be worked out jointly by the U.R.S.I. and C.C.I.R.

\section{Radio Wave Propagation}

The subject of wave propagation was of common interest to all the international bodies, although perhaps with different objects in view; the following recommendations may therefore be taken as being agreed generally by the various organisations concerned.

(a) Propagation through the ionosphere. In order to assist the study of the characteristics of the ionosphere, and the presentation of the results of ionospheric soundings, a detailed list of symbols and related nomenclature was drawn up and recommended for general adoption. Various details in the technique of carrying out vertical incidence soundings were revised in order to secure uniformity in practice at ionospheric observatories. There was general agreement that the density of ionospheric recording stations over the world should be increased, particularly along the three lines of longitude, $150^{\circ} \mathrm{E}$., $20^{\circ} \mathrm{E}$. and $70^{\circ} \mathrm{W}$.

The Brussels meeting of the Mixed Commission on the Ionosphere was presided over by Sir Edward Appleton, and in the course of its six sessions it surveyed in some detail our present knowledge of the ionosphere as obtained by direct radio exploration, and also by studies of auroras and geomagnetic phenomena. A number of resolutions were drawn up for consideration by the appropriate international scientific unions, with the view of enhancing the correlation of the characteristics of the ionosphere with geophysical and astrophysical phenomena.

At all the conferences there was universal agreement on the need for encouraging theoretical and experimental research on the mode of propagation of radio waves through the ionosphere, involving an increased and more precise knowledge of the absorption in the various regions, which is essential to the success of the forecasting of communication conditions. Particular attention was directed to the need for studying the technique of obtaining warning of disturbed conditions in the ionosphere, and communicating this to the practical user.

(b) Propagation through the troposphere. There was complete agreement at the Stockholm and London Conferences that it was necessary to proceed as rapidly as possible with the study of the propagation of waves at all frequencies above $30 \mathrm{Mc} . / \mathrm{s} .$, in order to ensure the best and most efficient use of this end of the radio-frequency spectrum. At the lower end of this range, it is sometimes necessary to take ionospheric conditions into account; but in general at these frequencies, it is the propagation of such waves over the ground and the obstacles on it, and through the lower atmosphere, that is much more important in connexion with the practical applications of very short waves. It was recommended that simultaneous studies of radio-wave propagation and the associated meteorological conditions should be undertaken on as wide a basis as possible, and that the appropriate scientific radio and meteorological organisations should study the relevant characteristics of the troposphere in all parts of the world. In this connexion the need was expressed for improved techniques for measuring the vertical and horizontal gradients of temperature and humidity in the lower atmosphere, and the variations of these gradients with time and place. It was considered that the time is approaching when a suitable standard nomen. clature might be drawn up for this subject, together with a uniform method of presenting both the radio and meteorological results.

These general recommendations were confirmed and elaborated by the Stockholm meeting of the Joint Commission on Radio-Meteorology, which held two technical sessions under the presidency of Dr. C. R. Burrows, of Cornell University. It was agreed that this Commission should direct its attention, as opportunity arose, to the theoretical and experimental determination of those properties of the lower atmosphere which affect radio propagation. These were deemed to include the study of storm detection by radar, and the location of sources of atmospherics by radio methods, as well as the actual transmission of radio-waves for communication or other purposes.

(c) Long-wave propagation. Following the lead given by the international bodies, the London Conference recommended that those Commonwealth countries in a position to do so should carry out a study of long waves propagated along the ground and through the ionosphere, and should seek the co-operation of other members of the Commonwealth when necessary. Partly in this connexion, it was considered important to increase our knowledge of the electrical constants of the ground, and all Commonwealth countries were urged to collect all appropriate information on this subject and arrange for its adequate distribution; and the United Kingdom was asked to prepare a survey of existing knowledge of the electrical constants of the ground at radio frequencies.

\section{Radio Noise}

In addition to the remarks already made above on this subject, the C.C.I.R. considered that atmospheric radio noise imposes one of the most important limitations on communications, and that therefore the study of such noise should be pursued on as wide a basis as possible. The conclusions agreed with those of the other bodies in recommending that meteorological studies should be undertaken to provide a knowledge of the distribution and nature of thunderstorms and the atmospherics originating from them. Investigations of the propagation of atmospheric disturbances and of the wave-forms and magnitude of the radio noise should be made in association with measurements of the direction of arrival at the receiver. Attention should also be given to the measurement of noise characteristics and their effects on receiving equipment in the frequency. range $10 \mathrm{kc} . / \mathrm{s}$. to $30 \mathrm{Mc} . / \mathrm{s}$., with particular reference to the range $10-300 \mathrm{kc} . / \mathrm{s}$.

The Commonwealth Conference endorsed the above recommendations and agreed to support the United Kingdom in the continuation and extension of a world survey of atmospheric noise-level by a subjective measuring method until the technique can be improved. It was further suggested that, in the interests of saving man-power and of ensuring that the quality of the data be as good as possible, particular consideration should be given by the United Kingdom to restricting the time schedule of such observations to the minimum necessary to obtain an adequate representative sample.

All meetings agreed that the work at present being conducted on solar and cosmic noise in various countries should continue on the existing lines. 


\section{Conclusion}

The above notes are intended as only a general survey of the main conclusions of the conferences, and a more detailed consideration of the various recommendations must await the publication of the proceedings of the meetings in the usual manner. Apart from the actual committee work leading to these results, the various conferences provided the usual informal opportunities for meeting contem. porary workers in other countries. The meetings in Sweden also enabled delegates to visit certain research and manufacturing organisations in Stockholm and Gothenburg.

R. L. Sмrth-Rose

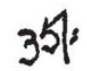

\section{LARGE-SCALE VERTICAL MOTION IN THE ATMOSPHERE}

$\mathrm{A}^{2}$ T a meeting of the Royal Meteorological Society on February 16, the subject for discussion was large-scale vertical at hospheric motion. In opening, Mr. J.K. Bannon stessed the importance of the rising and sinking of Mrge masses of air in atmospheric dynamics and Replained the relatively small attention given to vartifal mutio by meteorologists by the

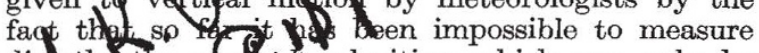
dirfetly the vertigal velocities, which can only be infersed, and that with difficulty. $\mathrm{He}$ went on to descripe a method of estimating up-currents from the rate of rainfall ${ }^{1}$, depending on the approximate equality of the rate of release of precipitation from a mass of rising air and the rate at which the saturation vapour content of the same air decreases as the temperature falls due to adiabatic expansion (that is, neglecting the changing water content of the cloud particles, which is small except in convection clouds). This method can be applied in cases of steady rising currents over a wide area (thirty miles square or more), and examples of results obtained from rainfall records in the Hebrides show that upcurrents in the lower and middle troposphere are of the order of $10-20 \mathrm{~cm}$./sec. in typical disturbances of the North Atlantic.

Mr. J. S. Sawyer then gave a brief description of two other methods of deducing vertical atmospheric movement. The first, that of Graham $^{2}$, requires a network of upper air observations of temperature and wind at regular time intervals. The horizontal motion between consecutive times of upper air observations being known, temperature changes unexplained by horizontal movement are assumed to be due to changes in height, and to take place adiabatically; and hence the vertical motion in the period may be inferred. The method is quick and may be used by the weather forecaster; the results are consistent with other phenomena such as rain (up currents). The second method, which Mr. Sawyer has applied to several cases in the neighbourhood of the British Isles, depends on the relation between vertical motion and the divergence of the horizontal wind field (the equation of continuity), and between the divergence of the horizontal wind field and the rate of change of the vertical component of vorticity (the vorticity equation). Several approximations must be made, but even so the technique is rather laborious and the method is only suited to research. Notwithstanding the approximations, the results obtained agree qualitatively with expectations, up- currents being deduced over rain areas and downcurrents over anticyclones; Graham's method gave comparable results. As emphasized later in the discussion by Dr. R. C. Sutcliffe, this vorticity method requires only knowledge of the pressure field-at more than one level, of course--and can be employed when wind observations are lacking.

Prof. P. A. Sheppard then gave a preliminary account of work being carried out under him in the Department of Meteorology of the Imperial College of Science and Technology by Mr. H. A. G. van Ufford and others. The eight radar wind-finding stations in the British Isles may be grouped to form seven triangles with sides of the order of 200-300 miles in length. The wind observations at the corners of these triangles (specially supplied by the Director, Meteorological Office, to the nearest degree in direction and the nearest knot in speed) were used to evaluate the horizontal divergence over each triangle, at $100 \mathrm{mb}$. intervals, between pressure-levels of $900 \mathrm{mb}$. and $200 \mathrm{mb}$, that is, approximately between 3,000 and $40,000 \mathrm{ft}$.; by the equation of continuity the vertical motion at each level was deduced from the horizontal divergence. The months December 1947-February 1948, inclusive, were investigated, and the large amount of data so obtained is still being analysed.

A few examples of results obtained were given. The weather of December 1947 was mainly anticyclonic over southern England, that of January 1948 very disturbed and cyclonic; frequency curves of the distribution of $\rho w$ (where $p$ is air density, $w$ is vertical velocity) for both the lower and upper troposphere reflect this, showing a preponderance of downcurrents in the south of the British Isles in the first month; in the January, both in the north and the south of the country, almost equal numbers of up and down currents occurred, and larger vertical velocities were more frequent. Prof. Sheppard also demonstrated curves showing the distribution with height of the mean up and down velocities for January 1948 over central England. When there was general ascent below $500 \mathrm{mb}$. the maximum of just over $7 \mathrm{~cm}$. $/ \mathrm{sec}$. occurred between 600 and $500 \mathrm{mb}$., that is, about $16,000 \mathrm{ft}$.; with general sub. sidence in the troposphere, the maximum was between 6 and $7 \mathrm{~cm}$./sec. and occurred between 500 and $400 \mathrm{mb}$. (about $20,000 \mathrm{ft}$.). It is noteworthy, he said, that in both cases the mean up and down currents, respectively, at tropopause-level are about $4 \mathrm{~cm}$. $/ \mathrm{sec}$. As well as the statistical results, which Prof. Sheppard stressed were the most important and significant outcome of the investigation, the distribution of vertical velocity was demonstrated for a few individual occasions, agreeing well with the general features of the weather (rainfall, development of ridges of high pressure, etc.). Velocities, both up and down, of up to $30-40 \mathrm{~cm}$. $/$ sec. were deduced even in the lower stratosphere, though $10-20 \mathrm{~cm} . / \mathrm{sec}$. were more usual maxima.

Mr. M. K. Miles said that, in using Graham's simple method, it is necessary to remember its limitations; as the author admits, it does not always lead to one definite value of vertical motion, and also the deduced velocity is an average over a considerable time, usually 6-12 hours. A comparison with Bannon's method, which tends to under-estimate the up current, and with a direct evaluation from horizontal wind observations, in one particular case, showed that Graham's method considerably under-estimates the vertical velocity. 